\title{
Prevalence of Musculoskeletal Pain and Postural Deformity in Papad Making Women -A Cross-Sectional Observational Study
}

\author{
Rekha B. Marbate*, Tejaswini C. Gedam, Shobha Bhave, Umanjali Damke \\ P. T. School and Center Govt. Medical College, Nagpur, MUHS, Nashik \\ Email: ^rekha.marbate@gmail.com, gedamteju@gmail.com
}

How to cite this paper: Marbate, R.B., Gedam, T.C., Bhave, S. and Damke, U. (2019) Prevalence of Musculoskeletal Pain and Postural Deformity in Papad Making Women-A Cross-Sectional Observational Study. Pain Studies and Treatment, 7, 21-31. https://doi.org/10.4236/pst.2019.72002

Received: April 4, 2019

Accepted: April 26, 2019

Published: April 29, 2019

Copyright $\odot 2019$ by author(s) and Scientific Research Publishing Inc. This work is licensed under the Creative Commons Attribution International License (CC BY 4.0).

http://creativecommons.org/licenses/by/4.0/

\begin{abstract}
Aim and Objective: To study musculoskeletal problems like musculoskeletal pain, postural deformity and nerve radiculopathy in women engaged in $\mathrm{Pa}$ pad making by clinical assessment. Methodology: A cross-sectional observational survey carried out at Shri. Mahila Gruh Udyog Lijjat Papad, Nandanvan, Nagpur (2014). 50 female subjects were selected for the study. After taking permission from factory in-charge, the survey was conducted at the factory site and subjects were explained about the study in details in language they can understand. Consent form was obtained by subjects to participate. Data were collected by interview and clinical examination of women engaged in this occupation, As per proforma of musculoskeletal examination. Result: Almost 37 subjects out of 50 complaints about low back pain as a chief complaint followed by neck pain in 34, thoracic kyphosis was more profound postural deviation seen in 10 subjects. Paraspinal and calf muscle spasm is more common. Radiating pain and numbness more in dominant hand suggestive of involvement of median nerve were confirmed by Upper Limb Traction Test [ULTT]. Discussion: Socioeconomic status greatly influences the working needs of women. Shri. Mahila Gruh Udyog Lijjat Papad factory provides a platform for Women Empowerment. Faulty posture adoption for longer duration during work gives rise to various musculoskeletal problems. Conclusion: $74 \%$ of the study population has low back pain as a chief musculoskeletal problem. $34 \%$ present with postural deviation and $82 \%$ belong to poor socioeconomic scale.
\end{abstract}

\section{Keywords}

Women Working in Papad Making Industry, Musculoskeletal Pain, Postural Deviation 


\section{Introduction}

In developing countries, great efforts are directed towards the development of small industries as the engine for their economic growth. According to WHO, over 1000 million people worldwide are employed in small scale industries [1].

The "Papad Making Industry of India" is one such industry which has provided ample opportunity of employment for the women of lower socio-economic class. "Shri Mahila Gruh Udyog Lijjat Papad" is one of the oldest Papad making industries of India, women working in this small scale industries are from lower socio-economic class and preferred to work from home. Though such industries are identified with women empowerment in India [2] [3] [4] [5], the employees are found to have not subjected to occupational health and safety provision. As a result, they suffer from various health problems [1] [5].

The women engaged in "Papad Making" industry prepared the "Papad" and delivered it to the company for further packaging and distribution through dealers. No machinery was used at the production level and everything was done manually from rolling of Papad at home to packing in the factory. While rolling Papad on Chakla, they used to sit on the ground with folding leg at their knee and hip and continuous forward bending posture for rolling Papad. In this posture, they sit for several minutes to hours, which causes increased strain on their back and Thoraco-lumbar region as reported by working women in that industry (see Figure 1) [5]. As explained by working women about their procedure of preparation, they need extra effort to roll Papad than normal Roti making, because dough to make Papad was comparatively hard and need more upper extremity strength along with back muscle. This faulty adaptive posture leads to protective spasm over Trapezius, Biceps, Hamstring and Calf muscle. Due to spasm, mobility was hampered and cause muscle imbalance [6] [7]. According to the explanation of Janda and his colleague, muscle imbalance resulting in upper crossed syndrome and lower crossed syndrome can be seen in this working women [5] [6] [8] [9].

These women were presents with tight Trapezius, Pectoral's, Hamstring and Gastronomies. This muscle imbalance led to postural deformity like exaggerated thoracic kyphosis, reduced lumbar lordosis and scoliosis due to derangement and rotation of spinal vertebrae [8]. Repetitive strain over back and upper cervical due to faulty posture caused nerve compression. The epidemiological cross-sectional study by Chen et al. concluded that there was a significant association between seat inclination and the use of lumbar support with low back pain [10] [11]. There are various studies available to show that sitting without lumbar support and bending posture increases Disc pressure and electromyography activities of back muscles [4] [10], so do the body parts involved in women working in Papad Making industry [12]. Hence the aim of this study is to check for the prevalence of various musculoskeletal problems in $\mathrm{Pa}$ pad-Making women. 


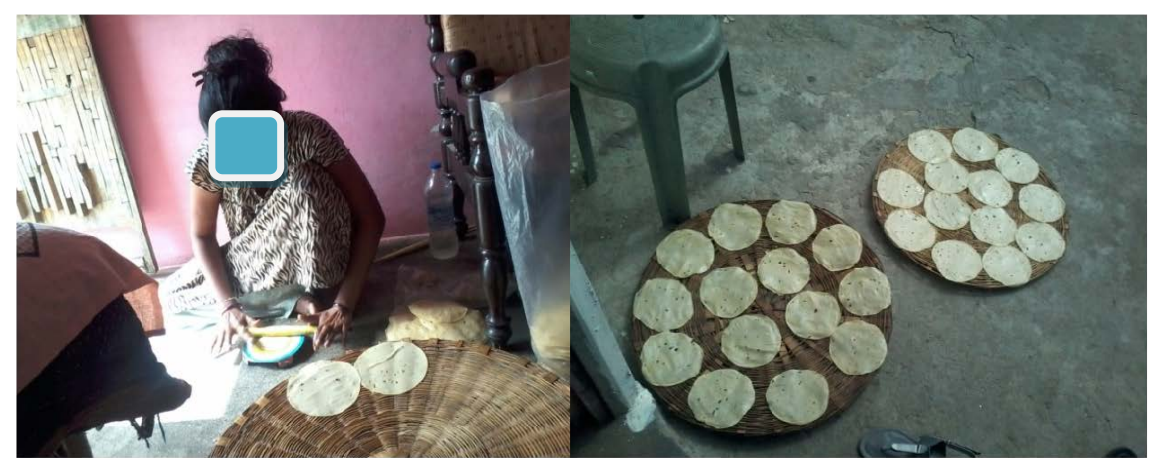

Figure 1. Women rolling Papad at home, sitting on the floor with forward bending shoulder protracted, wrist flexed with faulty lower limb posturing (original image).

The informal sector and small-scale industries in particular, are subjected to numerous workplace hazards [7] [13] and health hazards. These women require attention and modification in their traditional way of the method of preparation, as this ignorance can cause many musculoskeletal problems and pain. This ultimately results in deterioration in health and working capacities [12] [13]. In order to identify the occupational health hazards in the population of "Papad" Making women, this study was carried out. In this study, an attempt has been made to find out the musculoskeletal problem of the women engaged in "Papad Making" industry.

\section{Methodology and Procedure}

A Cross-sectional observational study was conducted on women working in one of the branches of the oldest Papad making industry in India named "Shri. Mahila Gruh Udyog Lijjat Papad”, Nandanvan, Nagpur (Oct 2014). After receiving permission letter from our institution, we planned a meeting to industry manager to make discussion about our study. We provided detailed explanation about our study and its importance, to seek permission to conduct this study on their workers at their workplace. After receiving permission letter, a survey was conducted. After providing detail information about study benefits, and written consent was obtained by all women ready to participate. A short interview questionnaire was assigned to all women for screening. Out of 110 women employers, only those women were included who involved in Papad rolling work with age group of 16 - 60 years, working for at least 6 months in this industry regularly and work for $\geq 5$ hours a day. Women with neurological, cardiopulmonary and orthopedic conditions were excluded. Data were collected by interview questionnaire for inclusion in the study population. Total 50 women were selected for clinical examination after screening interviews. Kuppuswamy scale 2011 revised was used to score and grade the socioeconomic status (SES) of each participant [score 26 - 29 upper class, 16 - 25 upper middle, 11 - 15 lower middle, 5 - 10 upper lower, $<5$ lower]. Clinical examination was carried out to check for musculoskeletal problem as per proforma given in Annexure. 
Pain was graded on Visual analogue scale of 10 [1-no pain, 5-moderate pain affecting activities, 10-extreme pain to tolerate]. Postural deviation was observed or assessed in standing position using plumb line as a reference of alignment for the body and deviations were noted accordingly as an exaggerated kyphosis or reduced or exaggerated lordosis. In posterior view, deviations of vertebral line with reference to plumb line were considered as scoliotic. Upper Limb and Lower Limb Traction Test was performed on participant sitting on chair and checked for tingling and numbness.

\begin{tabular}{ll}
\hline Nerve tested & Test position and sequence \\
\hline Median nerve & $\begin{array}{l}\text { shoulder is stabilized, Shoulder abduction, wrist and finger extension, } \\
\text { forearm supination, shoulder external rotation, elbow extension, cervical } \\
\text { side flexion }\end{array}$ \\
shoulder depression, elbow extension, medial rotation of whole arm, wrist, \\
finger, and thumb flexion \\
Radial nerve & $\begin{array}{l}\text { Shoulder depression, shoulder abduction, shoulder external rotation, wrist } \\
\text { and finger extension, elbow flexion, shoulder abduction }\end{array}$ \\
Ulnar nerve & $\begin{array}{l}\text { Supine lying, medial hip rotation, then flexion with knee extended } \\
\text { Sciatic nerve }\end{array}$ \\
$\begin{array}{l}\text { Supine lying, medial hip rotation, and then flexion with knee extended, } \\
\text { ankle planter flexion and foot inversion. }\end{array}$ \\
$\begin{array}{l}\text { Patient lying prone, affected knee full flexed and maintained for } 45 \text { seconds } \\
\text { if full flexion cannot be performed, the hip may be brought into extension. A } \\
\text { positive test shows shooting pain }\end{array}$ \\
Femoral nerve
\end{tabular}

After collecting, Data were tabulated in different tables and respective graphs were obtained to show the impact of their occupation on their musculoskeletal system. Screening and clinical examination were carried out by a team of 4 physiotherapist in group

At the end of clinical examination, a brief session of ergonomic advice and exercise were educated by Physiotherapy professionals.

\section{Result}

Graph 1 showed the demographic data and socioeconomic status (Graded according to Kuppuswamy Scale 2011) and age of the working women and their economic statuses were arranged as Table 1. It showed that there was a maximum number [ $82 \%$ of total study population] of working women aged between 16 and 45 from poor socioeconomic status [ $86 \%$ of total study population].

Table 2 showed data arranged with respect to pain region involved in Papad making women result was obtained as, $74 \%$ of women are reported back pain as a chief complaint followed by $68 \%$ of women complaints pain in her neck. Other regions as shoulder, elbow, wrist, hip, knee and ankles were also involved to some extent.

Table 3 showed kyphosis was the most prevalent postural deformity in women involved in rolling Papad work, out of 50 women 10 showed mild to mod- 
erate kyphotic posture at thoracic level. 10 women presented with reduced normal lumber lordotic curvature and 2 women presented with mild scoliosis.

Table 4 showed that Median nerve radiculopathy was more common in women engaged in Papad rolling work, followed by femoral nerve and sciatic nerve involvement, though Radial, Ulnar and Peroneal nerve were not much affected.

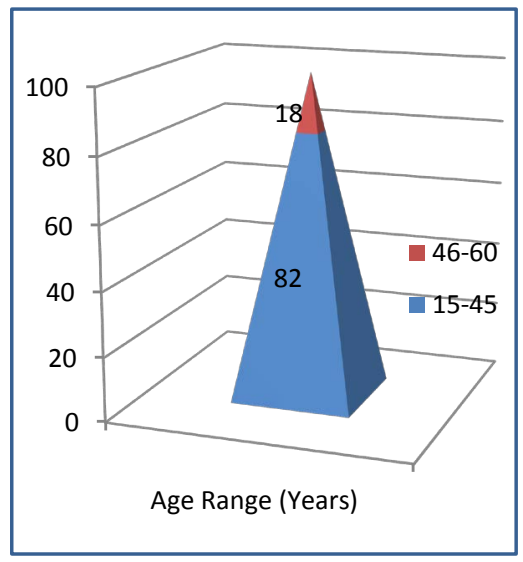

(a)

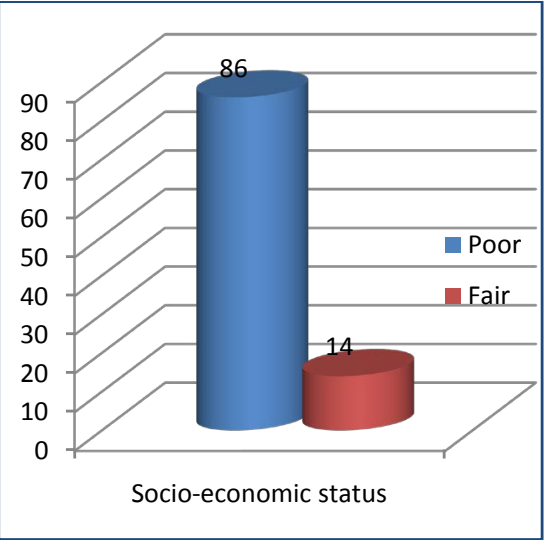

(b)

Graph 1. (a) Age range; (b) Socioeconomic status.

Table 1. Socio-demographic profile of study population where $n=50$.

\begin{tabular}{ccc}
\hline Age Range(Years) & No. of population & \% of population \\
\hline $16-45$ & 41 & 82 \\
$46-60$ & 09 & 18 \\
Socio-economic Status & & 86 \\
upper lower and lower[poor] & 43 & 14 \\
Lower middle [Fair] & 07 & \\
\hline
\end{tabular}

Table 2. Musculoskeletal problems of study population $(n=50)$ multiple response, show pain site involved as chief complaints.

\begin{tabular}{ccc}
\hline Pain site & No. of population & \% of population \\
Neck & 34 & 68 \\
Shoulder & 24 & 48 \\
Elbow & 15 & 30 \\
Wrist & 16 & 32 \\
Lower back & 18 & 74 \\
Hip & 8 & 16 \\
Knees & 37 & 48 \\
Ankle & 24 & 18 \\
\hline
\end{tabular}


Table 3. Postural deformities seen in study population where $\mathrm{n}=50$.

\begin{tabular}{ccc}
\hline Deformity & No. of population & \% of population \\
\hline Kyphosis & 10 & 20 \\
Lordosis & 05 & 10 \\
Scoliosis & 02 & 04 \\
\hline
\end{tabular}

Table 4. Neurological involvement: Radiating pain complaints assessed by ULTT and LLTT.

\begin{tabular}{ccc}
\hline Nerve involved & No. of subject & \% of population \\
\hline Radial & 04 & 08 \\
Ulnar & 05 & 10 \\
Median & 14 & 28 \\
Femoral & 08 & 16 \\
Sciatic & 07 & 14 \\
Peroneal & 02 & 04 \\
\hline
\end{tabular}

\section{Discussion}

This cross sectional survey was an attempt to find out the musculoskeletal problems faced by women actually engaged in rolling Papad work. Hence, survey was conducted at "Shri Mahila Gruh Udyog Lijjat Papad, Nagpur".

Musculoskeletal problems are the commonest health problem of the study population. Canadian women's health network has reported that musculoskeletal disorders are the most serious hazard of working women [12]. Out of 50 subjects 37 subjects complaints more about low back pain [LBP]. The cause behind LBP was continuous sitting in forward bending posture increasing disc pressure in spine and electromyographic activity of back muscle as reported by as explained by Nachemson AL (1981) and Anderson BJ, Ortengren [4] [5] [10]. Neck was found to be the second most commonly affected region followed by the low back as complained by 34 women. The cause of neck pain was increased neck muscle tension by continuous physical exertion, postural muscle imbalance and tensing the muscles unconsciously in response to stress. The study done by How-Ran Guo on women working in industries reported that musculoskeletal disorder of body part other than the back was of the neck, shoulder, hands and wrist [4] [13].

During work, Subjects sat in forward inclination of $10^{\circ}-30^{\circ}$, shoulders in $10^{\circ}$ $-30^{\circ}$ of abduction with forward flexion of $30^{\circ}-50^{\circ}$ \& elbow $10^{\circ}-20^{\circ}$ of flexion and extension and slight wrist extension and sat on the floor while rolling Papad. During rolling activity, there was a repetitive strain on elbow and wrist flexors and extensors, as a consequence of which there was spasm, joint pain and restricted ranges of motion. Nerve is often get compressed due to repetitive movement of hands and nerves of lower limbs may get compressed due to lum- 
bar plexus involvement because of increased disc pressure in lumbar region [4] [5] [10].

Also, 10 subjects showed mild to moderate Kyphosis and 5 subjects had Lordosis

While 2 subjects presented with Scoliosis. Dehghani et al. argued that subjects working with bending on the ground increased the percentage of kyphosis.

Neurological symptoms like peripheral radiculopathy were also there in complaint list of women assessed by upper and lower limb traction test, which revealed 14 subjects had median nerve stretch pain, 8 with femoral and 7 with sciatic pain. Bhrel et al. revealed that the repetitive strain of upper extremity resulted in median nerve compression [15] [16] [17] [18].

Socioeconomic status greatly influences the working needs of people. We found 41 people with Poor SES and 09 with Fair SES [5] [7]. In the "Papad Making" industry, there is no provision of retirement age, as the emphasis is on earning one's bread through daily work, all through one's life [1] [11]. Although such principle of this industry goes well with the self sufficiency of women, however it increases the duration of the occupational musculoskeletal problems.

\section{Conclusion}

This study concluded that, $74 \%$ of study population had Low back pain as a chief musculoskeletal complaint. $34 \%$ of study population presented with postural deviations. And almost $82 \%$ of study population was from poor socioeconomic status. Ignorance of women health led to many problems like absenteeism, low productivity and lack of quality product. Hence it is always needed to focus on their occupational health hazards on their musculoskeletal problems and improve their health status by providing quality treatment and awareness.

\section{Acknowledgement and Funding}

We are very thankful to manager In-charge Shri. Mahila Gruh Udyog Lijjat Papad", Nandanvan, Nagpur for their support and arrangement.

No any other funding.

\section{Conflicts of Interest}

The authors declare no conflicts of interest regarding the publication of this paper.

\section{References}

[1] WHO (1997) The Work Place. Health and Environment in Sustainable Development. Geneva.

[2] (2008) Shri Mahila Griha Udyog Lijjat Papad.

[3] Sharma, K. (2005) Women Employment. In: Sharma, S., Ed., Encyclopedia of Indian Women, Anmol Publications, New Delhi. http://en.wikipedia.org/wiki/Shri_Mahila_Griha_Udyog_Lijjat_Papad 
[4] Sunita, K. (2005) Gender Equality and Women's Empowerment in India. National Family Health Survey (NFHS-3) India 2005-06.

[5] Bhatnagar, D., Rsthore A., Torress, M.M. and Kannuungo, P. (2003) Empowering Women in Urban. Shri Mahila Griha Udyog Lijjat Papad, India.

[6] Anderson, B.J. and Ortengren, R. (1974) Myoelectric Back Muscle Activity during Sitting. Scandinavian Journal of Rehabilitation Medicine, Supplement, 3, 73-90.

[7] Levangie, P.K. and Norkin, C.C. (2011) Joint Structure and Functions: A Comprehensive Analysis (Textbook). F.A. Davis Company, Philadelphia.

[8] Forastieri, V. (2000) Women Worker and Gender Issue on Occupationional Safety and Health. Information Note, International labour Office, Geneva.

[9] Maggee, D.J. (2002) Orthopedic Physical Assessment (Textbook). 4th Edition, W.B. Saunders Co., Philadelphia.

[10] Kisner, C. and Colby, L.A. (2012) Therapeutic Exercises: Foundations and Techniqes (Textbook). F.A. Davis Company, Philadelphia.

[11] Nachemson, A.L. (1981) Disc Pressure Measurements. Spine, 6, 93-97. https://doi.org/10.1097/00007632-198101000-00020

[12] Chen, J.C., Dennerlein, J.T., Chang, C.C., Chang, W.R. and Christian, D.C. (2005) Seat Inclination, Use of Lumbar Support and Low Back Pain of Taxi Driver. Scandinavian Journal of Work, Environment \& Health, 31, 258-265. https://doi.org/10.5271/sjweh.881

[13] (2007) A Call to Action. Womens' Health at Work and Musculoskeletal Disorder. The Canadian Women's Health Network.

[14] Guo, H.R., Chang, Y.C., Yeh, W.Y., Chen, C.W. and Guo, Y.L. (2004) Prevalance of Musculoskeletal Disorder among Workers in Taiwan: A Nation Wide Study. Journal of Occupational Health, 46, 26-36. https://doi.org/10.1539/joh.46.26

[15] Park, K. (2015) Textbook of Preventive and Social Medicine. Bhanot Publishers, India.

[16] Brhel, P. (1999) Occupational Carpel Tunnel Syndrome. Occupational Health Industrial Medicine, 41, 287.

[17] Forsmann, M., Kadefors, R., Zhang, Q.X., Birch, L. and Palmerud, G. (1999) Motor-Unit Recruitment in the Trapezius Muscle during Arm Movements and in VDU Precision Work. International Journal of Industrial Ergonomics, 24, 619-630.

[18] Frost, P. and Andersen, J.H. (1999) Shoulder Impingement Syndrome in Relation to Shoulder Intensive Work. Occupational Health Industrial Medicine, 56, 494-498. 


\section{Annexure 1}

\section{ERGOMOMIC-ADVICE}

1) Workplace modification

- Patient is told to sit on low stool with cushion.

- Use of modified "chakla" and "Papad roller" Manufactured by MIT

(Maeers Institute of technology, Pune [cited 4 APRIL 2013, National Workshop on Occupational Health of Women .... WIEGO]

- Use of cot for drying "Papad". (Figure A1 and Figure A2)

2) Therapeutic exercises:-

- 10 minutes of stretching exercises after 2 hours of work.

- Strengthening Exercises of upper extremity, Lower extremity, abdominals and back extensors are taught to the patient.

- For subjects with back pain, back belt have been suggested, Avoid carrying heavy weights (instead of one heavy stock use two sacks of smaller weights).

- Perform self stretching exercises for Trapezius, Pectorals, Rf \& TA and trunk rotational exercises at home thrice a day. Active neural mobilization exercises to release nerve compression.

- Active exercises for upper extremity, lower extremity, and abdominal exercises.

- Do not stretch a muscle to the point of pain

- Breathe normally while stretching

3) Patient Education:-

- Sleeping on firm bed

- Maintain proper hygiene.

- Use of roll or pillow under lumbar to maintain the lumbar lordosis.

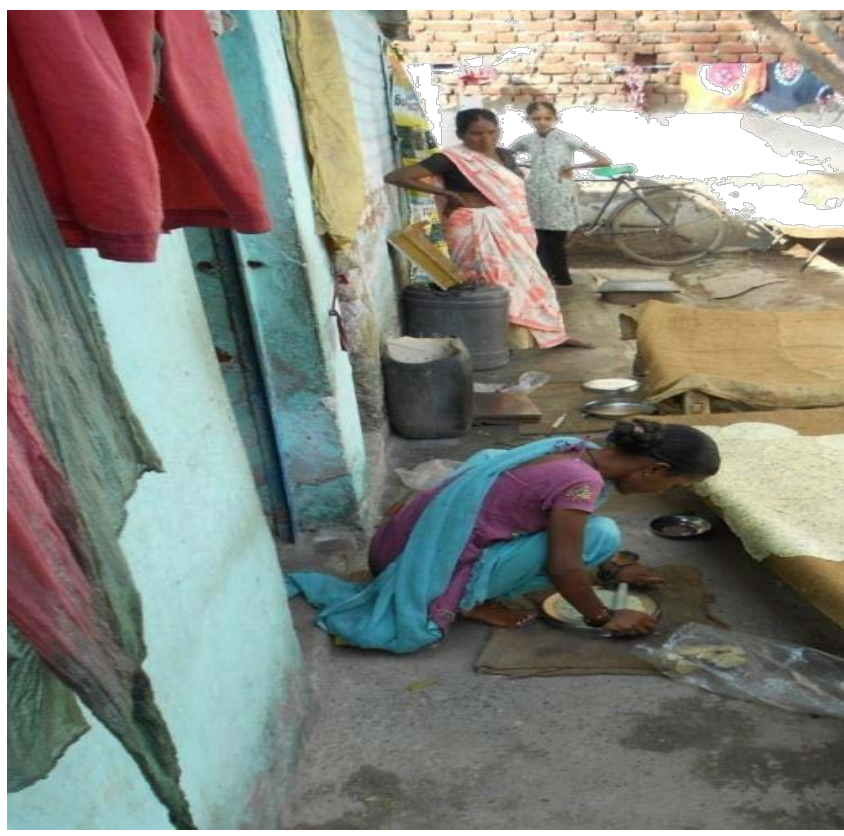

Figure A1. Before modification rolling Papad style adopted by woman. 


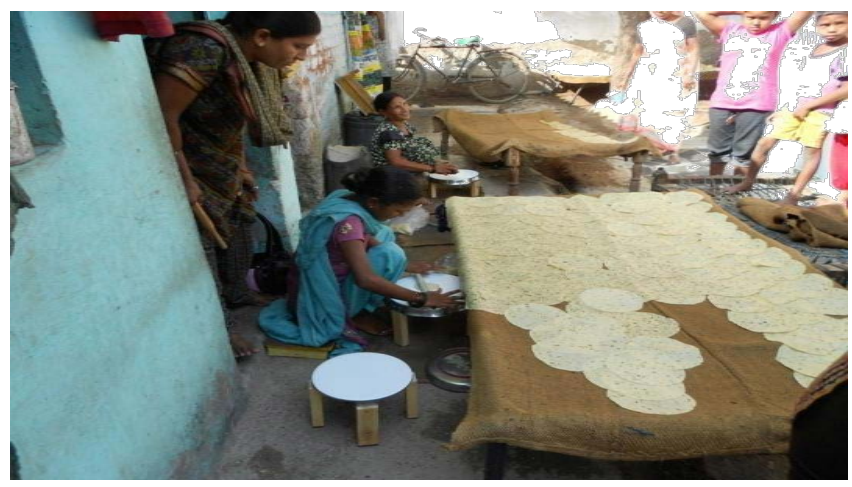

Figure A2. After modification rolling Papad style adopted by woman.

\section{Annexure 2}

\section{Interview questions:}

1) How long the subject is doing her job?

2) Regular or irregular during job?

3) Time duration of daily working?

4) Any rest between works? frequency and rest duration?

5) Any other systemic illness eg., HTN, DM, TB, HIV, Asthma?

6) Any musculoskeletal complaints due to their present job?

7) What is their socioeconomic status?

8) Any other previous injury, illness, trauma or surgery etc.?

\section{Annexure 3}

\section{Proforma}

Name:-

Dominance:-

Chief complaints:-

History of present illness:-

H/o: fall or trauma

Past history:-

Medical h/o:-

Personal h/o:-

Family h/o:-

Socioeconomic status:-

O/e:-

\section{Inspection}

A. Attitude:-

B. Posture, (if any postural deformity is seen)

Ant view:-

Lat view:-

Post view:-

\section{Palpation}

A. Spasm (if any):-
Age/sex:-

Residence:- 
B. Deformity (if any):-

C. Spino-scapular distance:

At superior angle

At mid scapular level

At inferior angle

Assessment of pain

Site:-

Onset:-

Duration:-

Nature:-

Aggravating factor-

Relieving factor-

Pain on visual analogue scale

Upper limb tension test (ULTT):

Median nerve, ulnar nerve, Radial nerve

Lower limb tension test:

Femoral and sciatic nerve 